\title{
HISTÓRIA E CONCEITOS FUNDAMENTAIS DE MODELOS ATÔMICOS INTRODUZIDOS NOS LIVROS DIDÁTICOS DE ENSINO MÉDIO E METODOLOIAS QUE POSSAM AUXILIAR UM APRENDIZADO MAIS SIGNIFICATIVO
}

\author{
Tatiane da Rocha Carias ${ }^{1}$ \\ Leynara Lessa Duarte ${ }^{2}$ \\ Terezinha Ayres-Pereira ${ }^{3}$
}

\begin{abstract}
Resumo: Este trabalho visa contextualizar conceitos históricos no desenvolvimento do conteúdo de modelos atômicos como forma de promover um aprendizado mais significativo. O objetivo deste trabalho é identificar as diferentes formas que são abordadas e propor uma metodologia que possa relacionar fatos históricos. Em três livros didáticos aprovados pelo PNLEM é analisados os conceitos históricos relacionados a esse tema. Após isso realizou-se um levantamento sobre os conceitos e a história dos Modelos atômicos. Mediante a análise dos livros pode-se observar a carência dos conceitos históricos que levaram ao surgimento e à evolução de cada modelo. Não abordam de forma coesa a história dos modelos atômicos, por isso se tornam necessários para que haja a inserção da história da ciência como a aplicação de uma metodologia diferenciada através de apresentação de vídeos e simulações à medida que os conceitos são ministrados e as aulas experimentais são realizadas.
\end{abstract}

Palavras-chave: Modelos atômicos; História da ciência; Livros didáticos.

\footnotetext{
${ }^{1}$ Química/UEMG - Ubá, Brasil. E-mail: tati_carias@hotmail.com.

2 Química/UEMG - Ubá, Brasil. E-mail: leynaraduarte@hotmail.com.

3 Química/UEMG - Ubá, Brasil. E-mail: tiayres@gmail.com.
} 